\title{
Two approaches to natural kinds
}

\author{
Judith K. Crane' ${ }^{1}$
}

Received: 4 October 2020 / Accepted: 21 July 2021 / Published online: 28 July 2021

() The Author(s) 2021

\begin{abstract}
Philosophical treatments of natural kinds are embedded in two distinct projects. I call these the philosophy of science approach and the philosophy of language approach. Each is characterized by its own set of philosophical questions, concerns, and assumptions. The kinds studied in the philosophy of science approach are projectible categories that can ground inductive inferences and scientific explanation. The kinds studied in the philosophy of language approach are the referential objects of a special linguistic category - natural kind terms - thought to refer directly. Philosophers may hope for a unified account addresses both sets of concerns. This paper argues that this cannot be done successfully. No single account can satisfy both the semantic objectives of the philosophy of language approach and the explanatory projects of the philosophy of science approach. After analyzing where the tensions arise, I make recommendations about assumptions and projects that are best abandoned, those that should be retained, and those that should go their separate ways. I also recommend adopting the disambiguating terminology of "scientific kinds" and "natural kinds" for the different notions of kinds developed in these different approaches.
\end{abstract}

Keywords Natural kinds - Scientific kinds $\cdot$ Homeostatic property cluster kinds · Natural kind terms $\cdot$ Pluralism $\cdot$ Essentialism $\cdot$ Realism $\cdot$ Rigid designation

\section{Introduction}

A philosophical approach to natural kinds is motivated by a family of questions, concerns, and assumptions that influence the nature of the accounts generated. The philosophy of language approach starts with the widely embraced "direct reference theory" of natural kind terms of the sort introduced by Kripke (1980) and Putnam (1975). It is more or less assumed that some version of a direct reference theory based on Kripke's "picture" is correct. The task for the theory of natural kinds then,

Judith K. Crane

jcrane@siue.edu

1 Department of Philosophy, Southern Illinois University Edwardsville, Edwardsville, IL, USA 
is to determine what natural kinds need to be like for a direct reference theory to work. The philosophy of language approach generates accounts of natural kinds characterized by metaphysical structures to which natural kind terms can directly refer. The philosophy of science approach focuses on the epistemological role of kinds in scientific investigations, how kinds are grounded in the causal structure of the world, how kinds can support inductive inferences, explanations, and causal interventions, and how working scientists do and should approach classification generally. The accounts of natural kinds generated in this approach tend to be domainrelative and pluralistic in order to accommodate the inductive and explanatory success of a variety of scientific practices. As a consequence, I argue, they do not have the sort of metaphysical structures that could ground a direct reference theory. This is not to say that they are ontologically inferior to the natural kinds of the philosophy of language approach, but that they cannot play the role of being the referential objects of "natural kind terms", as understood in the philosophy of language approach. While philosophers may hope for a unified account of natural kinds, this paper argues that the kinds of these two approaches are distinct and that no single account can satisfy both the semantic objectives of the philosophy of language approach and the explanatory projects of the philosophy of science approach. After analyzing where the tensions arise, I make recommendations about assumptions and projects that are best abandoned, those that should be retained, and those that should go their separate ways.

Hacking (2007) claims that contemporary philosophers use the term "natural kind" in so many ways that it no longer refers to any well-defined class. He believes the literature has devolved into a "scholastic twilight" from the "heady days of the 1970s when Saul Kripke and Hilary Putnam did so much to give sense and use to the idea of a natural kind" (p. 227). In my view the contemporary literature has accomplished a great deal. It is, however, bifurcated, and does not always display awareness of this bifurcation. If I am right, a terminological clarification is in order, so as to avoid using one term "natural kind" for different things. I will use what I take to be an appropriate terminological clarification at the beginning of my argument rather than at the end. The camp that will get new terminology is the philosophy of science camp. This is in part due to precedent. Some philosophers of science have preferred to step away from the "natural" label with its metaphysical connotations and talk about "investigative kinds," or just "kinds." "Explanatory kinds" or "epistemic kinds" might serve as well. So as not to appear to treat these as second-class kinds, I call them "scientific kinds" which hopefully connotes as much ontological seriousness as "natural". ${ }^{2}$ Because I think there remains a role for some

\footnotetext{
1 See Brigandt (2003) and Griffiths (2004). Hacking (2007) and Betzler (forthcoming) suggest that omitting mention of "natural" kinds will clarify discussions of classification in science. Ludwig (2018) recommends dropping the notion of "natural kind" entirely, along with the attempt to develop a general notion of natural kind.

2 My attempts to remain consistent with this usage create some awkwardness in the explication of some accounts that retain the term "natural kind." Khalidi (2013), for example, argues that because scientific kinds track real causal networks, they deserve to be called "natural kinds." Chang (2016) uses the label "natural," insisting that his account is naturalistic, even while nature is "framed by human perceptual and
} 
metaphysical structures characteristic of the kinds of the philosophy of language approach, and because of wide-spread usage, I will leave to them the name "natural kinds". I will use "natural kind term" for terms purported to have the distinctive dual-level semantics postulated by the direct reference theory, whereby we identify members of a kind by one set of (normally observable) features, but the term refers to underlying (often unknown) features.

The contemporary literature in which I am interested is quite large and spans roughly four decades. I do not intend to provide an exhaustive survey, nor to discuss every important contribution. I do intend to discuss representative examples drawn from each approach; these are contributions that I think highlight the relevant issues. ${ }^{3}$ My expositions of the two approaches are not in parallel. This reflects some of the differences between them. I see the philosophy of science approach as motivated by a certain kind of project - that of understanding the roles of classification in scientific practices. In the contemporary literature, Boyd has been instrumental in getting this project off the ground, and so my exposition starts with Boyd. I see the philosophy of language approach as starting with a set of assumptions about natural kind terms - that they are nondescriptional rigid designators whose reference is secured causally. My exposition starts with these assumptions and then works through the different versions of essentialism that are adopted to explain rigid designation.

\section{The philosophy of science approach}

The Homeostatic Property Cluster (HPC) account, introduced by Boyd (1989, 1990, 1991), is the most prominent and influential in the philosophy of science approach. In the last 30 years, it has been amended and modified, by Boyd as well others. A central motivation for the HPC account was to accommodate the natural kind-ness of biological species, for which essentialist claims seemed implausible. While there is no set of properties necessary and sufficient for belonging to a species, there are clusters of properties that tend to co-occur in homeostasis, and their homeostatic co-occurrences are often explained by underlying mechanisms. For the early Boyd $(1989,1991)$, the direct reference theory for natural kind terms was fully incorporated into the HPC account. Natural kind terms have a posteriori definitions rather

\footnotetext{
Footnote 2 (continued)

mental categories" (p. 43). I intend no change in the force of their claims about "natural kinds" in calling them "scientific kinds".

3 My classification of the philosophical literature is imperfect and may have unexpected results. LaPorte (2004, 2013) falls into the philosophy of language approach, even while modifying the standard view in light of a more informed picture of biological practices. Boyd (1989, 1991, 1999, 2010, 2021) falls into the philosophy of science approach even while concerns about reference remain central to his account. Ellis (2001) is hard to classify, as he claims to be not interested in theory of reference, but in the "scientific practice of theoretical identification" (p. 54). Yet his account is starkly different from others in the philosophy of science approach. See Beebee and Sarbbarton-Leary (2010) for an argument that Ellis, despite his focus on scientific classification, is "up to his neck in Kripkean commitments" (p. 175).
} 
than definitions established stipulatively by convention. Such definitions consist of property clusters together with any underlying mechanisms that maintain the clusters in homeostasis. Because we determine through scientific investigation which property clusters and underlying mechanisms belong in our species definitions, the account appears to fit nicely with the "dual-level" semantics of natural kind terms (discussed in the next section). That is, we identify members of a kind by observable features, but kind terms refer in virtue of discoverable but often undiscovered properties.

At the same time, explanation and induction are central to Boyd's account. The properties and mechanisms that belong in a kind definition do so because of their inductive and explanatory significance. According to Boyd (1999) "It is a truism that the philosophical theory of natural kinds is about how classificatory schemes come to contribute to the epistemic reliability of inductive and explanatory practices" (p. 146). This places Boyd squarely in my philosophy of science approach, despite his continuing concerns about reference. Moreover, as Boyd and other Boyd-inspired philosophers have developed accounts of scientific kinds, these accounts become increasingly disengaged from anything like a dogmatic commitment to the Direct Reference Theory. Boyd (1999, 2010, 2021) replaces his apparent earlier acceptance of a direct reference theory with his Accommodationist Theory: classificatory terms can effectively contribute to epistemically reliable inductive and explanatory practices only if those terms accommodate the causal powers of the phenomena studied by those practices. For Boyd (2010) "The accommodationist conception entails that descriptive, conceptual, and intentional factors figure fundamentally in establishing reference to natural kinds" (p. 223). Thus the later Boyd appears to adopt descriptivism. He maintains that the Accommodationist Theory is a causal theory since human conceptions and intentions are as much a part of the causal order as anything. His idea is that we can't separate our scientific usage of kind terms from the "disciplinary matrices" in which they are embedded. A disciplinary matrix is a family of methods, theories, concepts, and practices that inform a range of relevant questions and phenomena of interest. The conceptual background and specification of relevant questions and phenomena provided by a disciplinary matrix inform the content of scientific kind terms in ways that make essential contributions to reference. While most contributors to the philosophy of science approach don't address semantic issues to the extent that Boyd does, the idea of relativizing scientific kinds to domains of inquiry appears repeatedly. Once that idea is taken seriously, pluralism about kinds becomes plausible, since different classification schemes are appropriate to different domains of inquiry. Below I discuss several additional contributions to the philosophy of science approach (including recent work from Boyd) that de-emphasize the role of underlying mechanisms, relativize kinds to domains of inquiry, and are pluralistic with respect to scientific kinds.

Craver (2009) argues against the idea that mechanisms constitute the causal structure of the world in such a way that successful kind concepts track causal mechanisms and thereby carve nature at its joints (p. 575). The view that concerns Craver is a realist account of kinds that is also compatible with direct reference theories: we can identify members of a kind by an observable cluster of properties, but the reference of a kind term is determined by underlying mechanisms, which are independent 
of conventional ways of sorting into kinds. ${ }^{4}$ Craver objects that underlying mechanisms cannot carve out objective causal structures in the world because for any property cluster there is a variety of mechanisms in which it participates, including proximal and distal causal mechanisms, as well as the mechanisms that sustain the cluster. Craver writes: "one can be led to lump or split the same putative kind in different ways depending on which mechanism one consults in accommodating the taxonomy to the mechanistic structure of the world" (p. 583). Craver further argues that mechanisms can't play the role of individuating scientific kinds because mechanisms can themselves only be individuated relative to the purpose of the taxonomy for which they are employed. This is because both the boundaries between mechanisms and the level of abstraction at which they are characterized vary depending on what is needed for prediction, explanation, and control of various phenomena that scientists investigate. As there are no grounds for privileging one type or level of mechanism over others, recognizing a plurality of mechanisms leads to pluralism about scientific kinds. While a good scientific taxonomy needs to accommodate real causal structures in the world, it also will be responsive to the aims of the particular scientific enterprise in which it is embedded-what questions are asked, what phenomena are to be explained, what sort of interventions are relevant, and so forth (cf. Boyd's disciplinary matrices). Craver suggests a "simple causal theory" of scientific kinds that does not attempt to use underlying mechanisms to individuate kinds, and that is explicitly pluralistic.

Khalidi (2013) picks up on Craver's idea of a simple causal theory. For Khalidi, an account of scientific kinds should elucidate their role in explanation and inductive inference, and show how scientific kinds are projectible. Importantly, it should apply to special science kinds, which track causal patterns as much as do fundamental science kinds. For Khalidi, scientific kinds are "nodes in causal networks" (p. 200), characterized by a few central properties, such that when instantiated, they cause the instantiation of further properties. Khalidi argues that while there may be cases in which a mechanism serves to hold the network of properties together, there is often no single mechanism that does this, and the properties in the network don't necessarily need to be in homeostasis. What is necessary for scientific kinds is that they are projectible in such a way that we can make reliable inferences (including probabilistic ones) about members of a kind. Khalidi maintains that a simple causal theory makes more sense of special science kinds, in part because many special science kinds are multiply realizable. For example, Khalidi explores in detail the property viscosity and the kind Newtonian fluid from the field of fluid mechanics (pp. 82-92). Viscosity features in laws characterized at the macroscopic level (e.g., Fick's first law of diffusion, which incorporates the concepts of diffusion and concentration), though it is realized in different ways in liquids (chemical bonds), gasses (density and temperature), and porous solids (dimensions of pores). The kind Newtonian

\footnotetext{
${ }^{4}$ While Craver is concerned with the role of mechanisms in individuating kinds, his primary target is not necessarily Boyd, since Boyd does not think underlying mechanisms are always necessary for a property cluster to remain in homeostasis; nor is Boyd's realism of the kind articulated here. Nonetheless, it is an important idea, and a tempting one for a realist of this sort to take as the import of an HPC account.
} 
fluid is defined as a fluid with a constant viscosity; it includes substances whose viscosity is realized in these different ways. Thus there is no common micro-structural mechanism that unifies the kind Newtonian fluid. Rather, it is unified by the substantial generalizations that apply to it and its consequent projectibility. ${ }^{5}$

Ereshefsky and Reydon (2015) make a similar move in their acceptance of functional kinds, such as kinds of genes, which are characterized as DNA sequences that function in the production of molecular expression products. Because DNA sequences are often involved in multiple expression products, because the same DNA sequence may function in different ways (or not at all) in different organisms, and because several disconnected DNA sequences are often involved in a particular expression product, Ereshefshy and Reydon argue that "there is no unique mapping of molecular expression products onto DNA sequences" (p. 975). Genes are functionally defined kinds that nonetheless feature in non-trivial generalizations. For Ereshefsky and Reydon, scientific kinds are characterized in terms of the classificatory programs that generate them. Their account specifies necessary and sufficient conditions for classificatory programs to generate scientific kinds. Such a program would need to have both "sorting principles" and "motivating principles" where the motivating principles embody the purposes of the program's classification system and justify its sorting principles. The sorting principles in turn need to successfully promote the motivating principles. Second, either the sorting principles or the motivating principles would need to be empirically testable. Third, the program would need to be not degenerative relative to competing classificatory programs. That is, it ought to "produce additional classifications or extend existing classifications... and those classifications are empirically successful" (p. 982). This account is discipline-relative in that it recognizes scientific kinds by the sort of research programs in which they are embedded. This is a fairly permissive account, since there is considerable flexibility with respect to what counts as a scientific kind, including kinds characterized by function rather than by mechanisms or micro-structural properties.

Slater (2015) defends a "stable property cluster" (SPC) account according to which scientific kinds are characterized by property clusters that are "sufficiently stably coinstantiated to accommodate the inferential and explanatory uses to which particular sciences put such categories" (p. 396). This is meant as a modification of the HPC account that can apply more generally to scientific kinds, since underlying mechanisms are not needed for scientific kinds to be projectible and explanatory. It is also explicitly domain and context sensitive. For any area of scientific inquiry, only certain stable property clusters will be relevant to its inferential and explanatory projects. For this reason, Slater accepts a kind of pluralism, and sees little prospect that SPC kinds will carve nature along a single objective set of joints. There is no single set of stable property clusters to be carved. Nonetheless, for Slater, SPC

\footnotetext{
5 Khalidi's argument here is a response to those of Kim (1992) and Shapiro (2000) that if a kind is multiply realizable, it ought to be counted as multiple kinds because the broader kind will not feature in genuine, non-trivial laws and generalizations. See also Polger and Shapiro (2016) for further development of this line of argument against multiple realizability.
} 
kinds are "genuine features of the world" (p. 407) that various domains of inquiry use to facilitate and organize epistemic contact with the world.

Chang (2016) approaches kinds from the Boydian tradition in the sense of rejecting classical essentialism and focusing on how kinds operate in science. He rejects the idea that scientific kinds are independent of human cognition and practices, on the grounds that scientific inquiry is itself a human enterprise. For Chang, a scientific kind is a classificatory concept that is "sufficiently effective in aiding inquiry in the natural sciences" (p. 42). This is an even looser definition than those we have seen so far; it embraces domain sensitivity and pluralism, to the extent that it acknowledges the usefulness, for certain domains of inquiry, of categories that have been abandoned by modern science. Phlogiston was a perfectly good scientific kind in the domain of inquiry in which it was embedded. ${ }^{6}$ It did in fact aid scientific inquiry, and it could have developed into a modern scientific kind concept had certain lines of inquiry not been abandoned. I take a consequence of this to be that had chemical history gone differently, today's direct reference theorists would be happily asserting that the essence of phlogiston is easy-to-remove electrons, and that the term "phlogiston" was able to refer to such electrons when it was introduced as the substance that enabled combustion. But in the actual history, "phlogiston" never developed into a concept precise enough to designate easy-to-remove electrons, so the term did not refer to such electrons when it was introduced. Chang (2012) suggests that in a counter-factual history of chemistry the concept of phlogiston splits into one corresponding to the contemporary notion of chemical potential energy and another corresponding to electrons (pp. 47-48). Chang's scientific kinds are kinds that aid scientific inquiry, and are not characterized by any particular metaphysical structure. Like Chang, Magnus (2012) drops the idea that scientific kinds need to be tied to causal structures. Rather, they are domain-sensitive categories that allow scientific inquiry to achieve inductive and explanatory success (p. 48). For both Chang and Magnus, scientific kinds are descriptive categories that don't necessarily refer to causal structures. If they help to further inquiry, they count as scientific kinds.

Recent work by Boyd (2021) offers a general account of philosophically and scientifically significant kinds that are "manifestations of the ways in which the use of classificatory terms and concepts contributes to the accommodation of the inferential architectures of scientific (and other) disciplines to relevant causal structures" (pp. S2887-S2888). HPC kinds are but one category in this broader notion of a scientific kind. Thus so long as kind concepts help to guide our disciplinary practices toward a better alignment with relevant causal structures, they fall under this broader notion of scientific kind. This presumably applies to concepts like Chang's phlogiston, that (at least for a while) are not tied to any actual causal structures. It should also be broad enough to include functional and multiply realizable kinds like Newtonian fluid or kinds of genes.

\footnotetext{
${ }^{6}$ Chang uses the terminology "natural kind" throughout. To my ear, Chang's view sounds less startling with the change in terminology. I think it helps to remove the metaphysical connotations associated with the claim that phlogiston is a "natural kind."
} 
The discipline-relativity that appears repeatedly in these accounts of scientific kinds entails some manner of pluralism, since different classification schemes will be appropriate to different disciplines. It also entails some crosscutting kinds, since the classification schemes in different disciplines will focus on different phenomena. Khalidi (2013), for example, explicitly defends crosscutting kinds, noting that they are "ubiquitous in the sciences" (p. 70). In the special sciences in particular, identifying causal patterns that are explanatory of relevant phenomena "requires ignoring certain dissimilarities or focusing on certain aspects of causal reality to the exclusion of others" (p. 129). At the same time, there is a near uniformity (across both approaches, in fact) in professing realism with respect to kinds. The realism embraced in the philosophy of science approach rejects (sometimes explicitly) the idea that realism requires mind-independence. ${ }^{7}$ The role of scientific kinds in explaining the inductive and explanatory success of science, as well as the connection (in many cases at least) between classificatory concepts and causal structures in the world, is thought to be adequate grounds for realism about scientific kinds. Human minds and disciplinary projects are part of reality, so (the thought goes) discipline-relativity does not prevent scientific kinds from being real kinds.

How does the theory of reference fit in with the philosophy of science approach? Slater (2015) accepts that there is a "semantic cost" (p. 402) to his SPC account in the sense that it is unlikely to generate any claims about how reference works for natural kind terms. While I think it is true that SPC kinds lack the sort of metaphysical structure that can ground a direct reference theory (more on this later), the SPC account, as well as related accounts discussed in this section, does have implications for how reference to scientific kinds works. First, there should be some referential relation between scientific categories and causal structures. Boyd (1999, 2021) rightly insists that reference to causal structures is needed to account for the inductive and explanatory successes in a discipline. But if scientific kinds are characterized (at least in part) relative to specifications of explanatory projects, relevance, and other descriptive content, then the way scientific kind terms refer to causal structures must be explained at least in part through some sort of descriptive theory of reference. For example, Boyd (2021) develops a more nuanced account of reference for the classificatory terms of a discipline. He sees reference as a dialectical process rather than an event determined at a specific point in time. Over time, uses of classificatory terms in a discipline interact with relevant causal structures in ways that explain inferential and explanatory successes. It is neither the case that the external causal structures determine reference, nor that explicit definitions determine reference. Rather, in successful cases, there is a gradual convergence between the uses of terms in a discipline and the identification of causal structures that underwrite the inferential and explanatory success of those terms. In this process, it is clear that descriptive content from disciplinary matrices plays an essential role in the convergence between classificatory concepts and causal structures.

\footnotetext{
7 See for example arguments in Boyd (2021) Chang (2016) and Khalidi (2013).
} 
The above accounts (among others) constitute what I take to be a single approach to kinds. ${ }^{8}$ There is significant variety in the accounts generated in this approach, but also important commonalities. What unifies them as an approach is a central concern with classification as it is practiced in science, and with the epistemic value of scientific classificatory practices. Particular accounts of scientific kinds vary with respect to how scientific kinds are characterized, the extent to which they are tied to causal structures or micro-structures, and how broad or permissive the notion of a scientific kind is. They also resemble each other in important ways. The following is a good summary. It is itself a property cluster, characterizing the accounts in the category philosophy of science approach. I do not claim that every account in this approach must or does adopt all of these.

(a) Discipline-relativity Many philosophers in this approach (including all those discussed here) accept that scientific kinds cannot be separated from the disciplines in which they are embedded. As Betzler (forthcoming) argues, domain-relativity allows these accounts to assess the normative appropriateness of scientific kinds, by indexing kinds to domains that specify relevant phenomena and appropriate methods.

(b) Realism The realism of the philosophy of science approach is based on the idea that scientific kinds are embedded in successful scientific practices. While most profess to realism, accounts vary with respect to how responsive to real causal structures scientific kinds need to be. In some of the more pragmatic views (e.g., Chang, Magnus), the empirical success of the practices in which kinds are embedded is sufficient to ground their reality.

(c) Pluralism, permissiveness, and crosscutting kinds There are varying degrees of pluralism and permissiveness, depending on the inclusiveness of kind concepts, but some degree pluralism and the acceptance of some crosscutting is a consequence of discipline-relativity.

(d) Functional kinds and multiply realized kinds Many accounts do not require micro-structural criteria for individuating scientific kinds, and thus accept functional and multiply realized scientific kinds, which are individuated at the macro-level.

(e) Anti-essentialism Accounts in the philosophy of science approach have a general antipathy toward essentialism. I have not focused on this feature so far, because it is often hard to tell what form of essentialism is being rejected. The discussion in the next section of three kinds of essentialism adopted in the philosophy of language approach will help to illuminate the issue.

Once we go down the path of focusing on the roles of classification in scientific practice, our account of scientific kinds will likely take on many of these characteristics. By the end of this paper, I aim to establish that however accounts develop in

\footnotetext{
${ }^{8}$ Betzler's (forthcoming) characterization of "enthusiastic accounts" of kinds is substantially the same family that I place in the philosophy of science approach. For Betzler, enthusiastic accounts are characterized by their permissiveness, practice-orientation, epistemology-first stance, and expanded naturalism.
} 
this approach, its scientific kinds will not be the sort of entities that can be plugged into a direct reference theory.

\section{The philosophy of language approach}

What I call the philosophy of language approach starts with the assumption that some version of a direct reference theory for natural kind terms is correct. A direct reference theory is an account of natural kind terms that is committed to the following:

1. Natural kind terms are not descriptive Some direct reference theorists accept a certain amount of descriptive content in order to secure reference for natural kind terms. But a direct reference theory rejects any account according to which descriptions both constitute the meaning of a natural kind term and play a substantial role in determining reference.

2. Natural kind terms are rigid designators Rigidity is not nearly as straightforward for natural kind terms as it is for proper names. Consequently, there are different accounts of rigidity for natural kind terms.

3. A causal theory explains how reference is secured For natural kind terms, reference is normally secured through samples with which speakers are in contact.

One of the attractions of direct reference theories is their apparent naturalism. Rather than explaining reference in terms of "senses" or "intensions," whereby speakers grasp a description that determines an extension, reference is explained through causal relations with referents. By extending the direct reference theory from proper names to natural kind terms, philosophers hoped to provide a naturalistic account of the meanings of terms that ground scientific explanation and induction.

A non-descriptional proper name like "Aristotle" picks out a certain human being, regardless of whether the descriptions typically associated with the name are true of him. The name "Aristotle" causally latches onto a person and rigidly refers to him in every possible world where he exists, including worlds where Aristotle never becomes famous for anything. Some essentialist view is needed here to identify Aristotle across possible worlds - that is, something about Aristotle must be the same across possible worlds. For Kripke, "Aristotle" refers to the person (if there is such) in any possible world who originated from a particular egg and sperm. Thus, he adopts the "essentiality of origin" as the ontology that underwrites his account of the rigidity of proper names. Some version of essentialism is similarly required to underwrite the rigidity of natural kind terms. Different versions of rigidity employ different versions of essentialism. "Essentialism" about kinds is often rejected in the philosophy of science approach. As there are many possible essentialist theses that may be rejected, it is worth examining the essentialist theses that are employed by direct reference theories to see where tensions may arise between essentialism and scientific kinds. In what follows, I identify three essentialist theses by their role in 
supporting rigid designation for natural kind terms. Each account of essentialism and rigid designation will be assessed by considering its implications for scientific kinds, and by how well the resulting account succeeds in securing reference.

It was noted early on that rigid designation cannot work the same way for natural kind terms as it does for proper names. ${ }^{9}$ The thing designated by a proper name is its extension. The extension of a general term is normally thought to be the set of things to which it applies. Because there are different water samples and different tigers in different possible worlds, if natural kind terms designate their extensions, they are not rigid. The most commonly suggested alternate designatum for a natural kind term is an abstract property or universal (the kind), rather than the set of things that exemplify the kind. ${ }^{10}$ The first two versions of essentialism discussed below-Essentialism A and Essentialism B-make this move. The commitment to abstracta may already be too un-naturalistic for some, but it would be hasty to reject an account of rigid designation on that basis. Properties play important roles in explanation and induction, and we ought to leave science free to appeal to properties without needing to sort out their ontology. A third alternative, Essentialism $\mathrm{C}$, does not require reference to abstracta. In what follows, I consider how each of these essentialisms attempts to show how "water" is a rigid designator.

Essentialism A: "Water" designates the abstract kind water in every possible world, water being essentially the kind water (Salmon, 1981, 2003).

This version of essentialism may seem trivial. For Salmon, it is trivial, and that is its virtue because then no controversial essentialist claim is entailed by the direct reference theory. It makes no claim about what natural kind essences are like, and it makes no claim about individual essences of the sort that would ground individual persistence conditions. A consequence of this version of essentialism is that all simple kind terms are rigid designators. Just as "water" rigidly designates the water kind, "lawyer" rigidly designates the lawyer kind and "beer" rigidly designates the beer kind. This is not to say that natural kinds cannot be distinguished from other kinds, but that the distinction is independent of semantic theory. On this account, the direct reference theory has little to say about what is distinctive in the categories that ground scientific explanation and induction. Salmon may not object to this consequence, since his whole point was to reign in the direct reference theory by showing that it does not have controversial metaphysical implications.

Does Essentialism A succeed in showing how reference to a natural kind is secured? Without some additional apparatus, it does not, since it has a "qua" problem. This is the problem (so designated by Sterelny, 1983), of how a causal reference fixing for a natural kind term can zero in on the "right" kind while excluding others. The exemplars we are in contact with belong to many kinds, not all of which are natural. How does "water" get to designate the water kind and not the saltwater

\footnotetext{
9 See for example Cook (1980), Donnellan (1983), Forbes (1981), and Salmon (1981).

10 Mondadori (1978) and LaPorte (2013) think the extension of a natural kind term is this abstract property, rather than the set of things that exemplify it. So for them, all rigid designators designate their extensions.
} 
kind? How does "tiger" get to designate the tiger kind and not the predator kind? Salmon (1981) proposes what he takes to be two "axioms" of "natural kind theory" (which is independent of semantic theory): that an organism can belong to at most one species kind (p. 133), and that a substance can belong to at most one substance kind (p. 137). These are supposed to distinguish natural kinds from non-natural kinds since something can belong to multiple non-natural kinds-someone can be both a philosopher and coach—but can only belong to one species. In addition, to address the qua problem, we can add a minor semantic modification to the direct reference theory that Devitt and Sterelny (1999) employ for this purpose; terms like "water" and "tiger" need to be introduced with the intention that they be natural kind terms. Call this semantic modification SM. SM incorporates some descriptive content into natural kind terms, but only enough to stipulate that a term will function semantically as a natural kind term. If we add these supplementary claims (one semantic and one extra-semantic) to the trivial essentialist claim, the term "water" can pick out the only substance natural kind (if there is one) of which our exemplar is an instance.

The supplementary claims from natural kind theory, which are needed to solve the qua problem for Essentialism A, are deeply problematic for scientific kinds. In order to accommodate the causal structures that ground explanation and induction, scientific classifications include crosscutting kinds that violate Salmon's "axioms". The kind Newtonian fluid is explanatory, projectible, and subject to law-like generalizations, but is identified at a more abstract level than chemical composition. It is a substance kind that crosscuts chemical kinds. If we want our theory of natural kinds to be about scientific categories that ground explanation and induction, we need to recognize such crosscutting kinds. The axiom that an organism belongs to at most one species is more plausible, but given that there are many biological categories besides species-including other taxonomic ranks-the axiom can solve the qua problem for species names only if it is further stipulated that in introducing kind terms for organisms speakers are always intending to designate species. This is not plausible for ordinary speakers, who more often talk about genera, and it places severe limitations on what could count as kinds of organisms. There are also many more scientific kinds in biology besides species_-including kinds of genes, homologies, and ecological niches. Either these will not be natural kinds, or we will be introducing new axioms for every class of kinds. It is hard to see what would motivate such principles other than a need to make a particular semantic theory work. Although Salmon is keen on separating natural kind theory from semantic theory, his axioms of natural kind theory place unnecessary constraints on scientific kinds.

Essentialism B: "Water" designates the abstract kind water, a property that has an essential underlying nature (the $\mathrm{H}_{2} \mathrm{O}$ micro-structure) (LaPorte, 2004, 2013; Soames, 2002, 2007).

Essentialism B claims that natural kinds have less trivial essences, and that natural kind terms pick out these essences. It is a matter of the causal semantics of natural kind terms that they pick out underlying, usually unknown, natures, which are thought to explain or unify the observable features by which we identify typical samples of the kind. In every world where a kind is instantiated, all its members 
have this underlying nature. According to the causal theory, "water", as introduced into the language, picks out the underlying physical structure $\mathrm{H}_{2} \mathrm{O}$, so that in rigidly designating the water kind, "water" picks out $\mathrm{H}_{2} \mathrm{O}$ in every possible world. It is still not obvious that rigidity is a distinctive feature of natural kind terms, since the account does not rule out that "lawyer" rigidly designates the lawyer kind. (LaPorte (2004) accepts this.) There is, however, something semantically distinctive about natural kind terms, and hence about natural kinds. For Soames (2007), what makes a kind natural is that it is designated by a natural kind term, and natural kind terms are introduced by stipulations that fix the reference to underlying explanatory traits rather than to identifying features (pp. 339-340). Natural kind terms have a distinctive dual-level semantics, whereby observable features are used to secure reference, but reference gets fixed to underlying structures, which mark the boundaries between natural kinds. The essentialism involved in this account is the claim that natural kinds have underlying natures or basic physical constitutions, which can be picked out by contact with samples, and are such that all and only things with these natures belong to the kind. Kind essences are often conceived as micro-structural, though LaPorte (2004) accepts historical essences for species. Like Essentialism A, this account involves no essentialist claim regarding individuals of the sort that would ground individual persistence conditions. The essentialist claim of Essentialism B is that something would cease to belong to the kind $\mathrm{K}$ if it lost its K-essence, not that it would cease to exist without it. And Essentialism B specifies the sort of thing that would count as a K-essence (e.g., micro-structure, ancestral tree, etc.).

This account of what and how natural kind terms designate incorporates $S M$, so that speakers must have certain beliefs and intentions at least so far as they can stipulate that the term is supposed to refer to a natural kind. As we saw in discussing Essentialism A, $S M$ goes some way, but not the whole way, toward addressing the qua problem. To go the rest of the way, the account needs to show how natural kind terms fix on the "right" underlying properties-those that are in fact the essences of the natural kinds designated by natural kind terms. For Soames (2002, 2007), substance natural kind terms can do this because instances of them have unique basic physical constitutions, which unify and explain the identifying features associated with the substance and are essential to the substance.

The underlying structure that is essential to the kind water is presumed to be molecular-being composed of $\mathrm{H}_{2} \mathrm{O}$. A number of philosophers ${ }^{11}$ have pointed out that this claim is problematic. A mere collection of $\mathrm{H}_{2} \mathrm{O}$ molecules would not generate the characteristic features of water. Rather, a more complex story, including a constant transfer of ions among molecules, as well as a trace number of isotopes in addition to $\mathrm{H}_{2} \mathrm{O}$, generate the characteristic macroscopic properties. ${ }^{12}$ This could be understood to suggest merely that we need to refine the simplistic description of the essence of water that philosophers typically express. But the problem is deeper

\footnotetext{
11 Hendry (2006), Needham (2000), van Brakel (2000), and Weisberg (2006).

12 According to Hendry (2006) "macroscopic bodies of water are complex and dynamic congeries of different molecular species, in which there is a constant dissociation of individual molecules, reassociation of ions, and formation, growth, and dissociation of oligomers" (p. 870).
} 
than that and goes to the heart of the qua problem. It is that micro-structure cannot do the work of individuating kinds independently of macro-level descriptions. Molecular composition offers an alluringly tidy way to carve nature. But if you are interested in the substance water and why it behaves as it does, then molecular composition carves in the wrong place. Needham (2000) argues that "there is a complexity and variety at the micro-level which is unified only if seen in relation to single macroscopically distinguished kinds" (p. 13). van Brakel (2000) argues for a macroscopic account of chemical substances on similar grounds. The problem is not that we cannot describe the complexity that informs the identity of water entirely in micro-terms. And there is no denying that micro-level descriptions offer illuminating explanations of macro-properties, such as the viscosity of water. The point is that those micro-level features are identified relative to the phenomena we are looking to explain. Given an antecedently recognized kind water, we can look for micro-structural mechanisms that explain the macro-properties characteristic of the kind. Nothing unifies these micro-structural mechanisms except that they explain features individuated macroscopically. Even if we identify water with a more complex micro-structure, this micro-structure would not be a unique basic physical constitution for any particular instance of water. A particular water sample has multiple and varied micro-properties. Only some of these explain the antecedently identified macro-properties characteristic of water. In cases where we can refer to relevant micro-structures without (yet) being able to describe them, we do so by antecedently isolating kinds and employing macro-level characterizations of them for essential semantic work. Because of the complexity and variety at the micro-level, the semantic work of the macro-level characterization does not fall away when we isolate relevant aspects of micro-structure. Even if we were to use entirely micro-structural language to describe water, we would be isolating those micro-features that are most illuminating as explanations of the macro-features.

The problem for Essentialism B is that in order to secure rigid designation, it is not sufficient that we can discover underlying structures (or historical properties) that necessitate that something with these "essences" has certain macro-properties (or belongs to a certain population). The "essence" has to be unique-the only basic physical constitution (or fundamental historical property) of instances of a kind, independently of how they are categorized and all the descriptive content that goes into that categorization. Physical and historical complexity make this assumption highly implausible. To address the qua problem and thus fix reference onto the right micro-structures (or historical properties), we need to incorporate macro-level descriptions, and employ them for substantive semantic work. Thus for Essentialism $\mathrm{B}$, a full solution to the qua problem requires more than minor modifications to the direct reference theory; it requires full-blown descriptive content.

Essentialism C: "Water" rigidly applies to water samples, each of which is a water sample in every possible world where it exists (Cook, 1980; Devitt, 2005; Devitt \& Sterelny, 1999).

Rather than treating kind terms as "name-like" designators of abstract kinds, this view treats them as general terms that are true of, or apply to, multiple objects. While kinds have different members in different worlds, if a kind is natural, its 
members belong to their kind essentially, so that the natural kind term applies to them in every world where they exist. Just as a proper name, say, "Aristotle" refers to a particular baby identified at a baptism by his essential origin, upon ostensively introducing a kind term such as "water," the term applies to samples identified by properties that are not only common to the samples (or most of them), but also essential to each (or most of them). In this way, "water" rigidly applies to everything in any possible world with that essential property, even if we do not know what that property is. This strategy makes rigidity a distinctive feature of natural kind terms, since the members of non-natural kinds, say lawyers, are not essentially lawyers.

Devitt and Sterelny (1999) are among the few direct reference theorists who take seriously the qua problem, and they do not claim to have fully solved it. Nonetheless, Essentialism $\mathrm{C}$ addresses the qua problem to some extent. Like Essentialism $\mathrm{B}$, the account incorporates as part of the semantics of natural kind terms the intention that they be natural kind terms $(S M)$, exhibiting a dual-level semantics such that samples are identified by one set of properties while underlying properties individuate the kind. In addition, Essentialism $C$ postulates sufficient metaphysical apparatus to narrow down the possible underlying properties that could serve to fix the reference of a natural kind term. Though the underlying properties of an individual substance or organism are complex and multi-leveled, we can rule out those that are not among its essential properties, and thus not relevant to its being a member of a natural kind. The aspects of structure that inform liquidity or salinity (even if all our samples are liquid salt water) are not what the term "water" fixes onto, since these are not essential to any particular water sample. Essentialism $\mathrm{C}$ could go all the way to solving the qua problem if we accept as well the view that any object can belong to at most one natural kind. If this were the case, natural kinds would provide a unique partitioning of the world, carving nature at a unique set of joints. Call this claim uniqueness. Adding uniqueness to any of the three Essentialist theses would solve the qua problem.

Few philosophers accept uniqueness, however, and for good reason. It severely limits the kinds that count as natural, and it surely discounts the vast majority of scientific kinds. Devitt acknowledges that things can belong to multiple natural kinds, with different sets of essential properties relevant to each. An organism may be a Eurasian otter, a mammal, a vertebrate, etc., and according to Devitt is essentially each of these things, with different sets of essential properties relevant to each classification. There is a weaker thesis than uniqueness that does have contemporary advocates, and that can help here. Brian Ellis (2001) maintains that "if anything belongs to two natural kinds, these natural kinds must both be members of a common genus" (p. 20). Call this claim hierarchy. Hierarchy does not recognize crosscutting kinds but allows for nested hierarchies of natural kinds ranging from more general to more specific. Hierarchy narrows the possibilities for what essences a natural kind term can refer to. Now we need only add, in addition to SM and hierarchy, content that specifies the hierarchical level of the kind we mean to refer to. This may be done by changing the sample set to include or exclude certain samples, changing the relevant macroscopic features that are used to pick out the samples, or adding a description of the category of the natural kind (e.g., a specification of what is meant by "biological species" or "chemical substance"). 
This position can be seen as a "compromise view" that both adds descriptive content to the semantics side and places restrictions on the metaphysics side, so that a natural kind term can pick out a definite referent. As with many compromises, it may satisfy few, being both too descriptional to be a genuine direct reference theory, and not sufficiently accommodating of scientific practices by ruling out crosscutting kinds. The lesson to be drawn from this is that the project of solving the qua problem for the direct reference theory, and the project of accommodating scientific inductive and explanatory projects, often work against each other. In order to solve the qua problem, we need to restrict what counts as a natural kind. In order to recognize the variety of causally efficacious and projectible scientific kinds, we need allow for pluralistic and crosscutting kinds that make the qua problem intractable.

The most fundamental problem with Essentialism $\mathrm{C}$, however, is that for most scientific kinds, it is not plausible that instances of them belong to their kind essentially. Essentialism $\mathrm{C}$ assumes that samples of $\mathrm{H}_{2} \mathrm{O}$ could not exist without being $\mathrm{H}_{2} \mathrm{O}$, that samples of elements such as gold could not exist without being gold, and that an organism could not exist without belonging to the species that it belongs to. Given the relative ease with which compounds can be split, it is not obvious why we should think that water samples are essentially water samples. The rarity of nuclear transmutation in readily observable regions of the universe makes the essentialist claim about elements seem more inviting, but it is no more plausible. Devitt (2008) defends intrinsic criteria for species membership, which would make the essentialist claim about organisms intuitive. However, if one adopts one of the relational species concepts (e.g., ecological, biological), membership in a species is a contingent matter, as LaPorte (2004) explains. A new species can emerge when a splinter group becomes geographically isolated from a larger population, resulting in adaptations to new ecological conditions and/or reproductive isolation. For any organism in the larger population, there are possible worlds in which it is in the splinter group and worlds in which it is not.

The philosophy of language approach is unified by the assumption that some version of a direct reference theory applies to natural kind terms, and by the effort to understand natural kinds in the context of such a semantic theory. There is significant variety among the accounts in this approach; I have focused on the different versions of essentialism that are offered to support the claim that natural kind terms are non-descriptional rigid designators. While there are other kinds of essentialism that are independent of rigid designation, and while each of these three essentialisms has variations, these three kinds of essentialism exhaust the logical possibilities for what is needed for natural kind terms to be rigid designators. This is not something I can prove, but I am aware of no other possibilities. Each of them has to address the qua problem. Essentialism A does this with the help of multiple substantive claims from natural kind theory, each of which would rule out crosscutting kinds. Essentialism B does this by adopting the claim that instances of natural kinds have unique fundamental properties independently of how they are classified. Essentialism $\mathrm{C}$ addresses the qua problem by claiming that instances of natural kinds belong to their kinds essentially. None of these claims is attractive from the point of view of the philosophy of science approach. 


\section{Tensions and compatibilities}

\subsection{Essentialism}

Accounts in the philosophy of science approach often claim to be anti-essentialist, though it is not always clear which essentialist claims are being rejected. Some may reject essentialism on the grounds that scientific categories defined in terms of necessary and sufficient conditions are not the norm in science. That version of essentialism plays no role in the philosophy of language approach, which from the start was eager to dispense with such definitions for natural kind concepts. Do the essentialist theses that are employed in the philosophy of language approach conflict with the predominant theses of the philosophy of science approach? There is no conflict with Essentialism A, which just says that each natural kind is essentially the kind that it is. It is a trivial form of essentialism that applies to abstract kinds generally. There remains the metaphysical question about whether scientific kinds and properties are abstract; if they are, then Essentialism A could be true of them. My objections to Essentialism A concerned auxiliary claims (Salmon's "axioms" of natural kind theory) that can be employed to solve the qua problem, but that are not plausible theses for scientific kinds. If scientific kinds have essences in the trivial sense, nothing rules out our being able to characterize at least some of those essences in terms of molecular composition or ancestral tree, of the sort that Essentialism B postulates. It is not Essentialism B itself that runs into conflict with the philosophy of science approach; it is the claim, needed for natural kind terms to be non-descriptional rigid designators, that instances of kinds have unique fundamental properties independently of the disciplinary frameworks that inform relevant questions and phenomena of interest. So far as Essentialisms A and B are concerned, the antipathy of the philosophy of science approach toward essentialism is not warranted. There are genuine conflicts, however, with the additional claims about natural kinds that are introduced to support rigid designation.

Essentialism $\mathrm{C}$ cannot be maintained as a general account of scientific kinds that are explanatory and projectible. There are too many such kinds for which it is not plausible that their instances belong to them essentially. However, one should not abandon the idea of individuals having essential properties without which they could not persist; the possibility of persisting individuals requires such individual essences. The challenge is to find grounds for individuals having properties essentially, independently of the ways we categorize them. Otherwise, our claims about persistence will appear to be dependent on conventional ways of classifying things, like the judgment that a bronze statue persists through oxidation but is destroyed upon melting. Individual essences of the sort that would ground persistence conditions as well as "natural" classifications would really need to be mind-independent. Identifying such individual essences will take serious metaphysical work, and if successful could potentially provide an account of mind-independent "natural" kinds. But such an account will likely be limited in scope, for example to elementary 
particles that do not undergo change. ${ }^{13}$ Essentialism C's commitment to individual essences by itself presents no conflict with the philosophy of science approach. It is the essential properties that it postulates in order to ground rigid designation that are implausible.

\subsection{Realism}

Philosophers across both approaches claim to be realists about natural kinds, so realism would appear to be a point of convergence. But "realism" is hardly univocal in philosophy, and its use in the natural kinds literatures is no exception. The two approaches use conceptions of realism that are quite different. Essentialisms A and B each add auxiliary claims in order to solve the qua problem and establish that natural kind terms are rigid designators. These claims posit objective, mind-independent classificatory structures, by stipulating either that each thing belongs to exactly one (category of) natural kind (Essentialism A), or that each thing has unique fundamental properties (Essentialism B) that determine its kind. Essentialism C also posits mind-independent classificatory structures, though it builds this into the essentialist claim that these are the properties that individuals could not exist without. Call this commitment to mind-independent structures that carve nature along a single set of joints natural kind realism. Natural kind realism grounds rigid designation for natural kind terms by providing structures that natural kind terms can refer to without descriptional content and while avoiding the qua problem.

The dominant accounts in the philosophy of science approach reject the mindindependent natural joints characteristic of natural kind realism; consequently, the kinds they identify do not have the sort of metaphysical structures that can ground rigid designation. The move toward pluralism, and toward accepting discipline-relative kinds, crosscutting kinds, functional kinds, and multiply realizable kinds means that if you want scientific kind terms to be non-descriptional rigid designators, you will have an intractable qua problem. If we drop the commitment to a direct reference theory for natural kind terms, natural kind realism loses much of its motivation. Nonetheless, "realism" is an important issue in the philosophy of science literature. But the realism at stake is scientific realism. Scientific realism requires that true scientific theories, and the concepts and categories they employ, are responsive to real aspects of the world. On the face of it, scientific realism does not require that such theories reflect a unique partitioning of the world. The realism debate within the philosophy of science approach tends to focus on differences in the breadth or permissiveness of kind concepts, and on the extent to which accounts are pragmatic. The more pragmatic accounts require only that a scientific kind be useful for scientific practices, while less pragmatic accounts require that they be connected to causal structures or mechanisms. Some worry that the more pragmatic accounts lack the metaphysical structure to ground the epistemic value of scientific kinds as

13 But see Crane (2012) for a defense of individual essential properties of organisms. 
projectible, explanatory, and inductively powerful. ${ }^{14}$ Adopting natural kind realism would be one way to ground the epistemic claims, though it is an unpopular one in this approach. The costs in terms of developing a widely applicable and useful theory would be significant.

\subsection{Semantics}

I presented three theses of direct reference theories, and raised problems for the first two, that natural kind terms are non-descriptive rigid designators. The third, that reference is secured through samples with which speakers are causally related, contains a potentially interesting insight. There is a good case to be made that many scientific terms have a dual-level semantic structure such that they are able to refer to hidden features of the world before the science catches up and can describe those features explicitly. I discuss here two categories of scientific terms that appear to behave in this way. In each case, the kind is not individuated by hidden features but by observable ones. The qua problem shows that in order for these terms to latch onto the right explanatory features, the right explananda need to be part of their descriptive content, so that such terms are in fact descriptional.

The standard way that a new species is named is by a sample, officially recorded and named in a museum. A species name refers to the species to which the sample belongs, even if we don't know much more about that species (though identification of a genus is required for an official binomial species name). For this to identify a particular population of organisms, we need not only the intention that our name be a species term $(S M)$, but we need to know what sort of thing a species is in order to identify a kind with an essence. A baptism for a newly discovered species could stipulate that "Genus species" is the name of the monophyletic group including this sample and originating with the most recent speciation event. What counts as a speciation event depends on the species concept adopted. There are several options (e.g., biological, ecological, phylogenetic), adopted in various fields of biology for various explanatory purposes. One needs a particular explanatory purpose to pick out a particular population by a species baptism. If that is left open, the name may not latch onto any determinate population.

Hendry (2010) argues that "something like Putnam's account of reference" (p. 138) works for the names of chemical elements (though probably not for compounds). In particular, nuclear charge, rather than atomic weight, determined the extensions of scientific terms for chemical elements long before the discovery of atomic nuclear charges. This is because chemists in the eighteenth and nineteenth centuries had sufficiently clear concepts of chemical behaviors and reactions, and a sufficiently clear concept of chemical composition, that their names for elements (Laviosier's "hydrogen" and "oxygen" for example) tracked the explanatory grounds of such chemical reactions and behaviors. It was discovered only in the twentieth century that nuclear charge, rather than atomic weight, is the appropriate explanatory

$\overline{14}$ See Betzler (forthcoming) for a helpful discussion of this point. 
ground. There is no qua problem in this account, precisely because the descriptive content of the eighteenth and nineteenth century scientific element names included a conception of chemical behavior and composition, so that the terms could fix on atomic numbers as the underlying explanations. In this story, that descriptive content plays a significant semantic role.

Though some scientific terms exhibit this dual-level semantics, it is not a general feature of scientific terms. Many scientific terms are introduced and used as explicitly descriptional, in such a way that their definitions express essential features of the kind, without appeal to further "underlying" properties. In general, any kind term that is introduced by scientists (not adopted from pre-scientific usage) and given an explicit definition will not exhibit a dual-level semantics. Nor will those scientific kind terms that are defined at the macro-level, or as multiply realizable functional kinds. If philosophers of language were to drop the first two theses of the direct reference theory, that natural kind terms are non-descriptional and rigid designators, the possibility remains for fruitful work on the third, as an account of the semantics of at least some scientific terms. This work could provide useful insights on how imprecise scientific terms can identify causal structures, as well as on meaning change and meaning constancy though the development of theories.

\section{Conclusion}

I have shown that a significant bifurcation in the natural kinds literature should be acknowledged, and that it warrants a terminological clarification. The philosophy of science approach would do well to accept that it has a distinct project from that of the philosophy of language approach, recognizing that its scientific kinds are not the sort of entities that can be plugged into a direct reference theory for kind terms. Discussions of "realism" should be clarified so that philosophers may comfortably reject the natural kind realism that postulates mind-independent classificatory structures corresponding to scientific kinds, and focus on significant debates about scientific realism that are relevant to controversies about the nature of scientific kinds. At the same time, there is no need to commit to anti-essentialism, at least not without clarification about which essentialism one is anti-. Many common versions of essentialism are entirely consistent with the dominant theses of the philosophy of science approach. In addition, there is no need to reject all mind-independent classificatory structures, even if such mind-independence is neither required nor plausible for most scientific kinds that concern philosophers in this approach.

The assumption that natural kind terms are rigid designators, which I characterized as central to the philosophy of language approach, should be rejected. This means that as an approach to natural kinds, the philosophy of language approach ought to be abandoned. The commitment to this aspect of the direct reference theory has probably hindered progress on its genuine insight that some scientific terms exhibit a dual-level semantics, referring to hidden features before science is able to describe those features explicitly. By dropping natural kind realism and scaling back on the generality of this semantic feature, helpful progress could be made on things like meaning change and meaning constancy through theory development. 
Lastly, there remains the metaphysical project of investigating kinds and objects that are natural in the sense of being independent of human classificatory schemes and explanatory projects. This will involve looking for naturalistic grounds for essential properties and persistence conditions that are independent of how things are classified and could thus ground a natural classification. Such kinds, as elusive as they may be, can with justification retain the name natural kinds. My recommendation is to cease looking for such kinds in a theory of reference, and to recognize that the discipline-relative scientific kinds employed in explanations and inductive inferences are not natural in this sense. They are real kinds that are sensitive to causal structures with which we interact epistemically, but they don't engage the deep metaphysical issues regarding individual essences or persistence conditions.

Acknowledgements I am very grateful to two anonymous referees for this journal who provided many insightful comments and suggestions on earlier drafts of this paper.

Open Access This article is licensed under a Creative Commons Attribution 4.0 International License, which permits use, sharing, adaptation, distribution and reproduction in any medium or format, as long as you give appropriate credit to the original author(s) and the source, provide a link to the Creative Commons licence, and indicate if changes were made. The images or other third party material in this article are included in the article's Creative Commons licence, unless indicated otherwise in a credit line to the material. If material is not included in the article's Creative Commons licence and your intended use is not permitted by statutory regulation or exceeds the permitted use, you will need to obtain permission directly from the copyright holder. To view a copy of this licence, visit http://creativecommons.org/licen ses/by/4.0/.

\section{References}

Beebee, H., \& Sarbbarton-Leary, N. (2010). On the abuse of the necessary a posteriori. In H. Beebee \& N. Sabbarton-Leary (Eds.), The semantics and metaphysics of natural kinds (pp. 159-178). Routledge.

Betzler, R. (forthcoming). Two sources of normativity in enthusiastic accounts of kinds. British Journal for the Philosophy of Science. https://doi.org/10.1086/715149.

Boyd, R. H. (1989). What realism implies and what it does not. Dialectica, 43, 5-29.

Boyd, R. H. (1990). Realism, conventionality, and 'realism about.' In G. Boolos (Ed.), Meaning and method: Essays in honor of Hilary Putnam (pp. 171-195). Cambridge University Press.

Boyd, R. H. (1991). Realism, anti-foundationalism, and the enthusiasm for natural kinds. Philosophical Studies, 61, 127-148.

Boyd, R. H. (1999). Homeostasis, species, and higher taxa. In R. A. Wilson (Ed.), Species: New interdisciplinary essays (pp. 141-185). MIT Press.

Boyd, R. H. (2010). Realism, natural kinds, and philosophical methods. In H. Beebee \& N. SabbartonLeary (Eds.), The Semantics and metaphysics of natural kinds (pp. 212-234). Routledge.

Boyd, R. H. (2021). Rethinking natural kinds, reference and truth: Towards more Correspondence with reality, not less. Synthese, 198(Suppl 12), S2863-S2903.

Brigandt, I. (2003). Species pluralism does not imply species eliminativism. Philosophy of Science, $70(5), 1305-1316$.

Chang, H. (2012). Is water H2O? Springer.

Chang, H. (2016). The rising of chemical natural kinds through epistemic iteration. In C. Kendig (Ed.), Natural kinds and classification in scientific practice (pp. 33-46). Routledge.

Cook, M. (1980). If 'cat' is a rigid designator, what does it designate? Philosophical Studies, 37, 61-64.

Crane, J. K. (2012). Biological-mereological coincidence. Philosophical Studies, 161(2), 309-325.

Craver, C. F. (2009). Mechanisms and natural kinds. Philosophical Psychology, 22(5), 575-594.

Devitt, M. (2005). Rigid application. Philosophical Studies, 125, 139-165. 
Devitt, M. (2008). Resurrecting biological essentialism. Philosophy of Science, 75, 344-382.

Devitt, M., \& Sterelny, K. (1999). Language and reality (2nd ed.). MIT Press.

Donnellan, K. S. (1983). Kripke and putnam on natural kind terms. In C. Ginet \& S. Shoemaker (Eds.), Knowledge and mind (pp. 84-104). Oxford University Press.

Ellis, B. (2001). Scientific essentialism. Cambridge University Press.

Ereshefsky, M., \& Reydon, T. A. C. (2015). Scientific kinds. Philosophical Studies, 172, 969-986.

Forbes, G. (1981). An anti-essentialist note on substances. Analysis, 41, 32-37.

Griffiths, P. E. (2004). Emotions as natural and normative kinds. Philosophy of Science, 71(5), 901-911.

Hacking, I. (2007). Natural kinds: Rosy Dawn, scholastic twilight. Royal Institute of Philosophy Supplement, 61, 203-239.

Hendry, R. F. (2006). Elements, compounds, and other chemical kinds. Philosophy of Science, 73(5), $864-875$.

Hendry, R. F. (2010). The elements and conceptual change. In H. Beebee \& N. Sabbarton-Leary (Eds.), The semantics and metaphysics of natural kinds (pp. 137-158). Routedge.

Khalidi, M. A. (2013). Natural categories and human kinds. Cambridge University Press.

Kim, J. (1992). Multiple realization and the metaphysics of reduction. Philosophy and Phenomenological Research, 52, 1-26.

Kripke, S. (1980). Naming and necessity. Harvard University Press.

LaPorte, J. (2004). Natural kinds and conceptual change. Cambridge University Press.

LaPorte, J. (2013). Rigid designation and theoretical entities. Oxford University Press.

Ludwig, D. (2018). Letting go of 'natural kind': Toward a multidimensional framework of nonarbitrary classification. Philosophy of Science, 85, 31-52.

Magnus, P. D. (2012). Scientific enquiry and natural kinds. Palgrave Macmillan.

Mondadori, F. (1978). Interpreting modal semantics. In F. Guenther \& C. Rohrer (Eds.), Studies in formal semantics (pp. 13-40). North-Holland Publishing Co.

Needham, P. (2000). What is water? Analysis, 60(1), 13-21.

Polger, T. W., \& Shapiro, L. A. (2016). The multiple realization book. Oxford University Press.

Putnam, H. (1975). The meaning of meaning. In H. Putnam (Ed.), Mind, language and reality: Philosophical papers (Vol. II, pp. 215-271). Cambridge University Press.

Salmon, N. (1981). Reference and essence. Princeton University Press.

Salmon, N. (2003). Naming, necessity, and beyond. Mind, 112(447), 475-492.

Shapiro, L. A. (2000). Multiple realizations. Journal of Philosophy, 97, 635-654.

Slater, M. H. (2015). Natural kindness. British Journal for the Philosophy of Science, 66, 375-411.

Soames, S. (2002). Beyond rigidity: The unfinished semantic agenda of naming and necessity. Oxford University Press.

Soames, S. (2007). What are natural kinds? Philosophical Topics, 35, 329-342.

Sterelny, K. (1983). Natural kind terms. Pacific Philosophical Quarterly, 64, 110-125.

van Brakel, J. (2000). Philosophy of chemistry: Between the manifest and the scientific image. Leuven University Press.

Weisberg, M. (2006). Water is not $\mathrm{H}_{2}$ O. In D. Baird, E. Scerri, \& L. McIntyre (Eds.), Philosophy of chemistry (pp. 337-345). Springer.

Publisher's Note Springer Nature remains neutral with regard to jurisdictional claims in published maps and institutional affiliations. 